\title{
Population differentiation in the barnacle Chthamalus malayensis: postglacial colonization and recent connectivity across the Pacific and Indian Oceans
}

\author{
Ling Ming Tsang ${ }^{1, * *}$, Benny K. K. Chan ${ }^{2, * *}$, Tsz Huen $\mathrm{Wu}^{1}$, Wai Chuen $\mathrm{Ng}^{3}$, \\ Tapas Chatterjee ${ }^{4}$, Gray A. Williams ${ }^{3}$, Ka Hou Chu ${ }^{1, *}$ \\ ${ }^{1}$ Department of Biology, The Chinese University of Hong Kong, Shatin, Hong Kong \\ ${ }^{2}$ Research Centre for Biodiversity, Academia Sinica, Taipei 115, Taiwan \\ ${ }^{3}$ The Swire Institute of Marine Science and School of Biological Sciences, The University of Hong Kong, Pokfulam Road, \\ Hong Kong \\ ${ }^{4}$ Department of Biology, Indian School of Learning, I.S.M. Annexe, P.O. - I.S.M., Dhanbad-826004, Jharkhand, India
}

\begin{abstract}
Chthamalus malayensis is a common intertidal acorn barnacle widely distributed in the Indo-West Pacific. Analysis of the mitochondrial cytochrome $c$ oxidase subunit I (COI) sequences of samples from its distribution range revealed 3 genetically differentiated clades: the South China Sea, Indo-Malay and Taiwan clades. The clades have an allopatric distribution and differed by $\sim 7.5$ to $14 \%$ in COI. They also differed in zonation patterns and abundances within vertical ranges. The genetic and ecological differences suggest that the 3 clades probably represent distinct species. There were signatures of postglacial demographic expansion, yet the timing of expansion varied among clades, which is attributable to the differences in their geographical distributions. The Indian Ocean population of the Indo-Malay clade apparently attained its present range by postglacial re-colonization from the Pacific and, as a result, genetic differentiation among populations in the 2 oceans is low $\left(\Phi_{\mathrm{CT}}=-0.01, \mathrm{p}=0.49\right)$. There were differences in cohort structure between populations in India and the Malay Peninsula. Together, this suggests a considerable level of contemporary gene flow over an evolutionary, but relatively restricted dispersal on an ecological time scale. Cohort structure also varied among Malaysia and Singapore, the South China Sea and Taiwan waters, indicating distinct larval supplies among the 3 clades, possibly determined by different ocean current systems. This physical dispersal of larvae interacts with local biological factors in determining the on-shore distribution and genetic structure of the barnacle populations. Our findings highlight the importance of combining ecological and genetic data to understand factors that mould biodiversity patterns.
\end{abstract}

KEY WORDS: Population connectivity · Demographic expansion · Cryptic species · Glaciation · Indo-West Pacific · Chthamalidae

\section{INTRODUCTION}

The diversity and genetic structure of species reflect long histories of speciation, driven by past tectonic events and recent dispersal and colonization processes after the last ice age (Avise 2000, Hewitt 2000). The extraordinarily high marine biodiversity in the IndoWest Pacific (IWP) is well known (Briggs 1999, Hughes et al. 2002) and has attracted the interests of evolutionary biologists and ecologists. Ancient tectonic events and more recent fluctuating sea levels during the Quaternary are believed to have promoted allopatric 
diversification in this region (Briggs 1999). As a result, there is a phylogeographic break between the Pacific and Indian Oceans in an array of widely distributed taxa (Benzie 1999). Genetic differentiation is believed to result from the repeated lowering of sea level during the Pleistocene glaciation, which restricted dispersal between the 2 oceans (Benzie 1999, Voris 2000). Yet, some taxa are highly genetically homogeneous across the 2 oceans (e.g. Lessios et al. 2003, Craig et al. 2007), which may be attributed to postglacial colonization of the Indian Ocean by Pacific Ocean populations (Lessios et al. 2003) or to high levels of present-day gene flow (Craig et al. 2007). Thus, taxon-specific ecological characteristics and the current connectivity among populations also contribute to determining the genetic structure and distribution pattern of a species.

On the other hand, molecular phylogeographic studies have also discovered a large number of cryptic species in the IWP (e.g. Meyer et al. 2005, Chan et al. 2007a). Although the IWP is already famous for its high biodiversity and endemism, diversity appears to be far higher than currently documented. This has important implications for conservation planning and evolutionary theory (Bickford et al. 2007), prompting more intensive studies in the region. Our recent studies revealed that the common intertidal acorn barnacle Tetraclita squamosa, which was once considered to be widely distributed in the IWP, is actually a species complex in which each biological species has a specific, restricted distribution in comparison to the whole complex (Chan et al. 2007a,b). Barnacles are major space occupiers and play important roles in community dynamics on rocky shores (Reimer 1976, Bertness et al. 1998). A poor understanding of species identities will hamper ecological studies of community-level interactions. Elucidating the distribution and genetic structures of species like barnacles and the processes governing observable patterns will greatly enhance knowledge of intertidal biogeography and community ecology.

Chthamalus malayensis Pilsbry 1916 is a common intertidal barnacle widely distributed throughout the IWP (Southward \& Newman 2003). The species is common in Indo-Malay and Australian waters and is also found in the Indian Ocean and western Pacific region; it varies little morphologically over its wide geographic range (Southward \& Newman 2003). However, given what we now know of the Tetraclita squamosa complex, it is possible that cryptic species are also present within the range of 'C. malayensis'. There have, for instance, been reports of differences in reproductive season among populations of C. malayensis (Koh et al. 2005, Yan et al. 2006). While C. malayensis in Singapore is reproductively active year round (Koh et al. 2005), individuals in Hong Kong only spawn during the summer (Yan et al. 2006). These differences have been attributed to climatic differences between the 2 areas, as populations in tropical Singapore experience only slight seasonal variation in contrast to those inhabiting the seasonal climate of Hong Kong (Yan et al. 2006). An alternative hypothesis, however, would be that the 2 populations represent 2 cryptic species with different life-history traits. To test this, detailed molecular and ecological studies are needed.

The wide distribution range of Chthamalus malayensis allows investigation of past and present-day connectivity of intertidal organisms in the IWP. Lowered sea levels during the Pleistocene glaciations exposed a large part of the Indo-Malay region (Voris 2000), where $C$. malayensis is now the most common barnacle. This retreat of the seas would have reduced habitat availability for intertidal species, leading to population bottlenecks and vicariance among fragmented populations. Following the retreat of glaciers, however, species were able to undergo range expansion, enabling reconnection of isolated populations. The level of contemporary connectivity among populations will determine whether any detectable genetic signature of isolation could be maintained and will also have important effects on population dynamics and ranges of different species (e.g. Pannacciulli et al. 1997, Craig et al. 2007). There is an increasing recognition that dispersal capacity alone is not a good indicator of connectivity (Taylor \& Hellberg 2003), promoting the need for more studies to elucidate the causal factors affecting population dynamics in the marine realm. Most studies to date have focused mainly on fishes, especially coral reef fishes (reviewed in Mora \& Sale 2002). There have been no large-scale studies on intertidal organisms, and C. malayensis provides a good opportunity to investigate connectivity among oceans.

We investigated genetic and ecological variation of Chthamalus malayensis in the IWP. We examined genetic differentiation using the DNA sequences of mitochondrial cytochrome $c$ oxidase subunit I (COI) among C. malayensis populations; $\mathrm{COI}$ has proved to be informative in phylogeographic studies of barnacles (e.g. Chan et al. 2007a, Tsang et al. 2007). We integrated these data with those on vertical zonation and cohort structure of $C$. malayensis in different regions. These molecular and ecological analyses specifically addressed the following questions: (1) Are C. malayensis populations genetically differentiated, perhaps into cryptic species? (2) Does C. malayensis have any genetic signature caused by the Pleistocene glaciations? (3) What is the level of connectivity among populations between and within the Pacific and Indian Oceans, and does this affect the genetic structure of the barnacle? 


\section{MATERIALS AND METHODS}

Sample collection. Chthamalus malayensis specimens were collected from 11 localities in the Indo-West Pacific, either through our own site visits or by local collaborators (Table 1, Fig. 1). During the site visits, we also conducted vertical zonation and cohort structure investigations at 8 of the localities: 2 in Taiwan (Hualien and Northeast Coast), 3 along the coast of southern China (Hong Kong and Hoi Ling Island in the Guangdong Province and Sanya in the Hainan Province), and 1 each in Malaysia (Mersing), Singapore (Sentosa Island) and India (Tranquebar). Ecological surveys were also conducted at Mahabalipuram (MM, $12^{\circ} 37^{\prime} \mathrm{N}, 80^{\circ} 12^{\prime} \mathrm{E}$ ) in India, but these specimens were not included in the genetic study. Ecological studies were not conducted at the other 3 sites included in the genetic analyses, i.e. Sri Chang Island in Thailand (TH), Langkawi Island (LK) in Malaysia, and south Sri Lanka (SL).

Vertical zonation and cohort structure. At each ecological sampling site, a $20 \mathrm{~m}$ stretch of shoreline was chosen. Six $20 \mathrm{~m}$ transects were set parallel to the shore at $\sim 2.5 \mathrm{~m}$ and $2.25 \mathrm{~m}$ (high shore), $\sim 2 \mathrm{~m}$ and $1.75 \mathrm{~m}$ (mid shore), $\sim 1.5 \mathrm{~m}$ and $1.25 \mathrm{~m}$ (low shore) above Chart Datum (CD), as judged from predicted tide tables. Maximum tidal range for all sites was $\sim 2.5 \mathrm{~m}$; therefore, the high, mid and low shore levels of all sites were comparable. At each level, digital photographs of 10 randomly positioned $15 \times 15 \mathrm{~cm}$

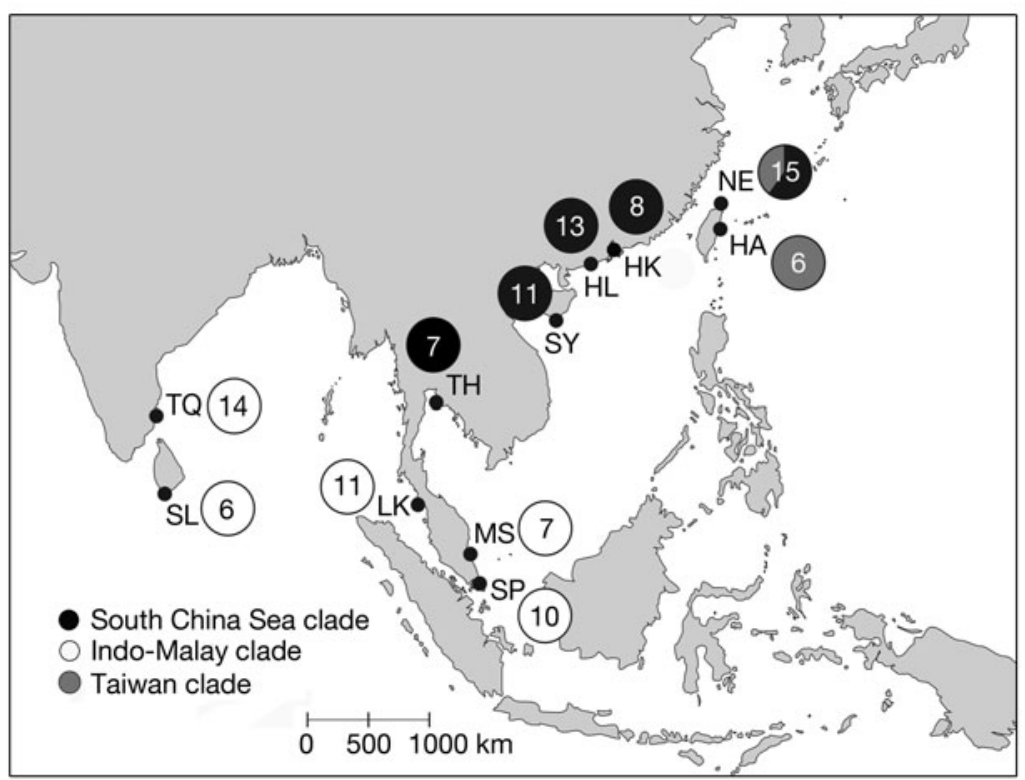

Fig. 1. Chthamalus malayensis. Sampling localities (capital letters). Clade distribution based on mitochondrial COI is shown inside each pie chart. Numbers within the pie charts indicate sample size. See Table 1 for abbreviations of localities

quadrats were taken. The density and percentage cover of Chthamalus malayensis in each quadrat was scored on each photograph. Spatial variation in cohort structure of C. malayensis was compared among Mahabalipuram and Tranquebar in India, Sentosa Island in Singapore, Mersing in Malaysia, Hong Kong and Hoi Ling Island in Guangdong, and Hualien and NE Coast in Taiwan, as these sites were all sampled from January to March 2007. Data from Sanya in Hainan were not included in the comparison, as sam-

Table 1. Chthamalus malayensis. Sample localities, abbreviations, sample sizes (n), and genetic diversity of COI (mitochondrial cytochrome $c$ oxidase subunit I) for each population: number of haplotypes, haplotype diversity (h \pm SD), nucleotide diversity $(\pi \pm \mathrm{SD})$, Tajima's $D$ and Fu's $F_{\mathrm{S} .}{ }^{*} \mathrm{p}<0.05,{ }^{* *} \mathrm{p}<0.01,{ }^{* * *} \mathrm{p}<0.001$

\begin{tabular}{|c|c|c|c|c|c|c|c|c|}
\hline Population & Abbreviation & Lat./Long. & $\mathrm{n}$ & $\begin{array}{c}\text { No. of } \\
\text { haplotypes }\end{array}$ & $\mathrm{h} \pm \mathrm{SD}$ & $\pi \pm \mathrm{SD}$ & $\begin{array}{c}\text { Tajima's } \\
D\end{array}$ & Fu's $F_{\mathrm{s}}$ \\
\hline \multicolumn{9}{|l|}{ Pacific Ocean } \\
\hline Northeast Coast, Taiwan & NE & $24^{\circ} 58^{\prime} \mathrm{N}, 121^{\circ} 55^{\prime} \mathrm{E}$ & 15 & 13 & & & & \\
\hline Taiwan clade & & & 6 & 4 & $0.800 \pm 0.172$ & $0.007 \pm 0.004$ & -1.22 & 0.85 \\
\hline South China Sea clade & & & 9 & 9 & $1.000 \pm 0.052$ & $0.013 \pm 0.008$ & -0.76 & $-3.26^{*}$ \\
\hline Hualien, Taiwan & HA & $23^{\circ} 28^{\prime} \mathrm{N}, 121^{\circ} 29^{\prime} \mathrm{E}$ & 6 & 6 & $1.000 \pm 0.096$ & $0.007 \pm 0.004$ & -0.94 & $-2.59^{*}$ \\
\hline Hong Kong, China & HK & $22^{\circ} 12^{\prime} \mathrm{N}, 114^{\circ} 13^{\prime} \mathrm{E}$ & 8 & 8 & $1.000 \pm 0.063$ & $0.013 \pm 0.008$ & -0.64 & $-2.74^{*}$ \\
\hline Hoi Ling Is., China & HL & $21^{\circ} 36^{\prime} \mathrm{N}, 111^{\circ} 54^{\prime} \mathrm{E}$ & 13 & 13 & $1.000 \pm 0.030$ & $0.015 \pm 0.009$ & -0.69 & $-6.09^{* *}$ \\
\hline Sanya, China & SY & $18^{\circ} 19^{\prime} \mathrm{N}, 109^{\circ} 45^{\prime} \mathrm{E}$ & 11 & 10 & $0.982 \pm 0.046$ & $0.010 \pm 0.006$ & -1.22 & $-3.54^{*}$ \\
\hline Sri Chang Is., Thailand & $\mathrm{TH}$ & $13^{\circ} 08^{\prime} \mathrm{N}, 100^{\circ} 48^{\prime} \mathrm{E}$ & 7 & 7 & $1.000 \pm 0.076$ & $0.014 \pm 0.009$ & -0.67 & -1.75 \\
\hline Mersing, Malaysia & MS & $2^{\circ} 26^{\prime} \mathrm{N}, 103^{\circ} 50^{\prime} \mathrm{E}$ & 7 & 7 & $1.000 \pm 0.076$ & $0.004 \pm 0.003$ & $-1.58^{*}$ & $-5.28^{* * *}$ \\
\hline Sentosa Is., Singapore & SP & $1^{\circ} 14^{\prime} \mathrm{N}, 103^{\circ} 50^{\prime} \mathrm{E}$ & 10 & 7 & $0.867 \pm 0.107$ & $0.004 \pm 0.003$ & -0.92 & -2.24 \\
\hline \multicolumn{9}{|l|}{ Indian Ocean } \\
\hline Langkawi Is., Malaysia & LK & $6^{\circ} 25^{\prime} \mathrm{N}, \quad 99^{\circ} 40^{\prime} \mathrm{E}$ & 11 & 7 & $0.873 \pm 0.089$ & $0.002 \pm 0.002$ & $-1.65^{*}$ & $-4.05^{* *}$ \\
\hline Tranquebar, India & TQ & $11^{\circ} 02^{\prime} \mathrm{N}, \quad 79^{\circ} 51^{\prime} \mathrm{E}$ & 14 & 7 & $0.802 \pm 0.094$ & $0.004 \pm 0.002$ & -1.15 & -1.76 \\
\hline South Sri Lanka & SL & $6^{\circ} 02^{\prime} \mathrm{N}, \quad 80^{\circ} 14^{\prime} \mathrm{E}$ & 6 & 6 & $1.000 \pm 0.096$ & $0.005 \pm 0.004$ & $-1.43^{*}$ & $-3.03^{*}$ \\
\hline
\end{tabular}


pling at this site was conducted in October 2006. The rostral-carinal basal diameter ( $\mathrm{R}-\mathrm{C}$ basal diameter) of C. malayensis in each quadrat was measured from the calibrated photographs using Sigma Scan Pro 5 (see Chan et al. 2008). Cohort structures were analysed using electronic length frequency analysis (ICLARM, see Chan \& Williams 2004).

DNA extraction, PCR and sequencing. Total genomic DNA was extracted from whole soft tissues of individual barnacles using the commercial QIAamp tissue kit (QIAGEN). Partial sequences of mitochondrial COI were amplified using the universal primers LCO1490 and HCO2198 (Folmer et al. 1994). The amplifications were conducted in a reaction mix containing $1 \mu \mathrm{l}$ of template DNA, $1 \times$ PCR reaction buffer, $2 \mathrm{mM} \mathrm{MgCl} 2,200 \mathrm{nM}$ of each primer, $200 \mu \mathrm{M}$ dNTPs, 1.5 units of Taq polymerase (Amersham) and doubledistilled $\mathrm{H}_{2} \mathrm{O}$ to a total volume of $50 \mu \mathrm{l}$. The PCR profile was as follows: $3 \mathrm{~min}$ at $94^{\circ} \mathrm{C}$ for initial denaturation, then 33 cycles of $30 \mathrm{~s}$ at $94^{\circ} \mathrm{C}, 30 \mathrm{~s}$ at $47^{\circ} \mathrm{C}, 1 \mathrm{~min}$ at $72^{\circ} \mathrm{C}$ with a final extension for $3 \mathrm{~min}$ at $72^{\circ} \mathrm{C}$. The PCR products were then purified using the QIAquick gel purification kit (QIAGEN) according to the manufacturer's instructions. Sequences were generated using the same set of primers and an Applied Biosystems (ABI) 3100 automated sequencer using the ABI bigdye ready-reaction mix kit, following the standard cycle sequencing protocol.

Phylogenetic analysis. Nucleotide sequences were aligned using CLUSTAL W (Thompson et al. 1994), and alignments were confirmed by translating sequences into amino acid sequences. Phylogenetic relationships between individuals were determined by neighbour-joining (NJ), based on analysis of Kimura 2-parameter (K2P) distance and using PAUP* v4.0 b10 (Swofford 2000) with Chthamalus moro and C. challengeri (collected from Hualien, Taiwan and Wakayama, Japan, respectively) as outgroups. The support for individual nodes was evaluated by 1000 bootstrap replicates. To determine the genealogical relationships among haplotypes, a haplotype network was constructed using the $95 \%$ parsimony criterion as implemented by the program TCS 1.13 (Clement et al. 2000).

Population genetic analysis. Haplotype diversity (h) and nucleotide diversity $(\pi)$ were calculated for each population and clade using ARLEQUIN 3.0 (Excoffier et al. 2005). Pairwise $\Phi_{\mathrm{ST}}$ values were calculated to estimate the level of gene flow among populations within each clade. To test the hypothesis of a phylogeographic break and reduced gene flow between the Indian and Pacific Ocean populations, genetic differentiation between populations from the 2 oceans was examined by an analysis of molecular variance (AMOVA, Excoffier et al. 1992) as implemented in the same program with K2P distance and 10000 random permutations to test for statistical significance. This analysis provided insight into the proportion of genetic variation attributable to within-population $\left(\Phi_{\mathrm{ST}}\right)$, withingroup $\left(\Phi_{\mathrm{SC}}\right)$, and among-group $\left(\Phi_{\mathrm{CT}}\right)$ differences.

Tajima's $D$ test (Tajima 1989) and Fu's $F_{\mathrm{S}}$ test (Fu 1997) in ARLEQUIN 3.0 were used to test for departures from mutation and drift equilibria expected for a selectively neutral marker. Negative $D$ and/or $F_{\mathrm{S}}$ values indicate an excess of low-frequency haplotypes, which may be an indication of rapid demographic expansion. Mismatch distribution analysis (Rogers \& Harpending 1992) was conducted with the same software. When a signature of rapid expansion (a unimodal distribution) was detected, we computed the parameter $\tau$, which was used to estimate the approximate timing of population expansion (Schneider \& Excoffier 1999). A divergence rate of $3.1 \%$ per million years in the COI locus between lineages was calibrated for a trans-isthmian Euraphia sister species pair; Euraphia is a genus closely related to Chthamalus (Wares 2001). As heterogeneity in substitution rate among lineages might lead to bias in the molecular clock, the expansion time obtained should be interpreted with caution and only provides evidence of a causal role of geological events on observed demographic changes.

\section{RESULTS}

\section{Vertical zonation}

Abundance and vertical zonation varied among Chthamalus malayensis populations from the 3 geographic regions: Indo-Malaysia $(\mathrm{MM}, \mathrm{TQ}, \mathrm{MS}$ and SP), southern China (HK, HL and SY) and Taiwan (HA and NE) (Fig. 2). In India, Malaysia and Singapore, C. malayensis was the major space occupier, with $>50 \%$ coverage on the shore and high abundance on the mid to low shore (Fig. 2). At the 3 sites in southern China, C. malayensis was abundant only on the high shore, with $\sim 50 \%$ coverage (Fig. 2). In Taiwan, C. malayensis was found from high to low shores, but abundance was low, with $<10 \%$ coverage (Fig. 2).

\section{Cohort structure}

Cohort structure varied among sites in India, Malaysia and Singapore, southern China and Taiwan. In India, the Chthamalus malayensis population comprised a single cohort, with a mean $\mathrm{R}-\mathrm{C}$ basal diameter of 3 to $4 \mathrm{~min}$ (Fig. 3). In Malaysia and Singapore, 

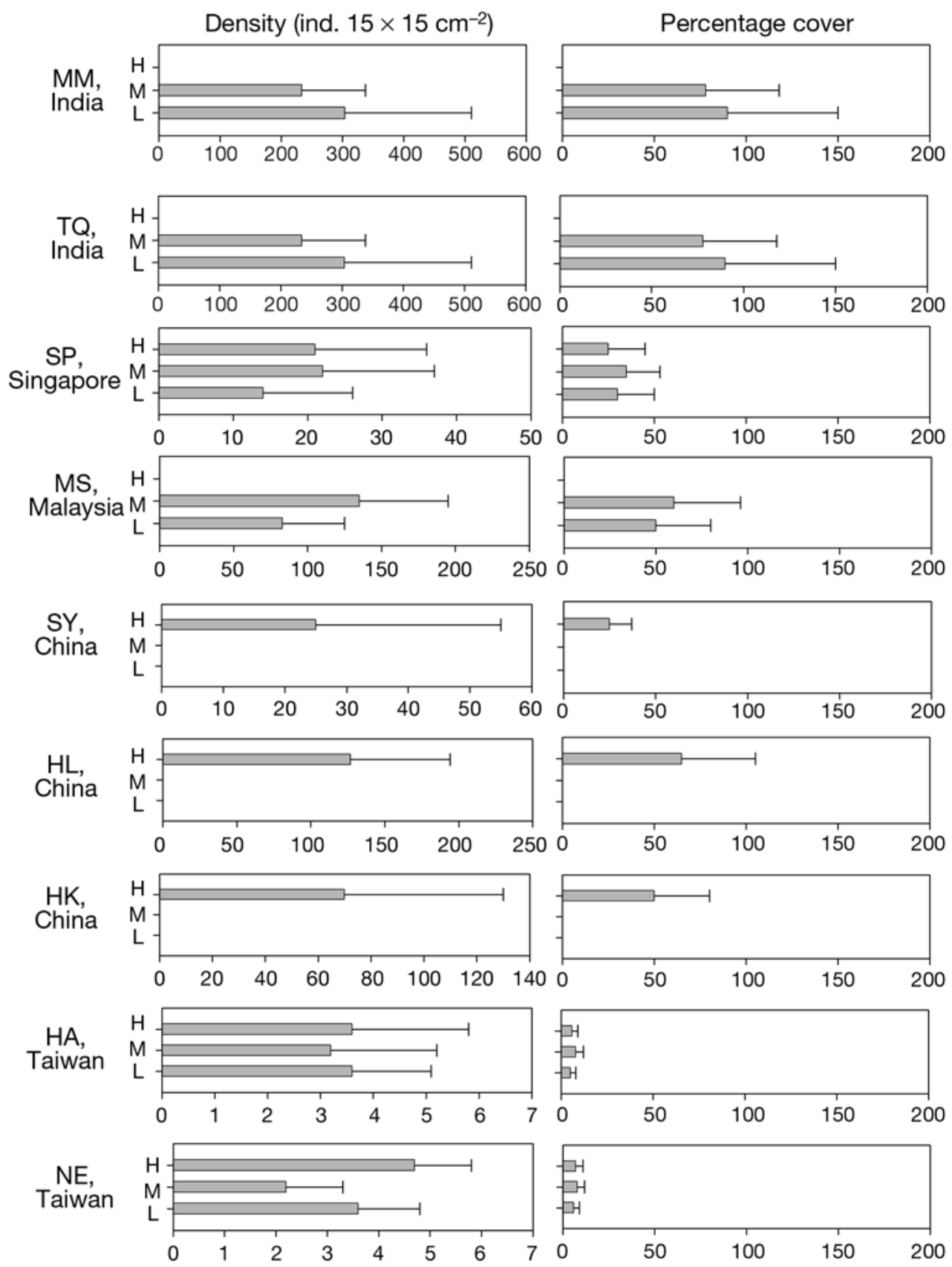

Fig. 2. Chthamalus malayensis. Variation in density (ind. $15 \times 15 \mathrm{~cm}^{-2}$ ) and percentage cover (mean $+\mathrm{SD}, \mathrm{n}=10$ ). MM: Mahabalipuram; see Table 1 for other abbreviations of localities

C. malayensis populations had 2 distinct cohorts, viz. a juvenile cohort with a mean $\mathrm{R}-\mathrm{C}$ basal diameter of $\sim 2$ $\mathrm{mm}$ and an older cohort with a mean $\mathrm{R}-\mathrm{C}$ basal diameter of $\sim 6$ to $8 \mathrm{~mm}$. In southern China, populations were dominated by a single cohort, with a mean $\mathrm{R}-\mathrm{C}$ basal diameter of $\sim 8 \mathrm{~mm}$, whilst a second, larger cohort was identified from Hong Kong (mean R-C basal diameter of $11.2 \mathrm{~mm}$ ). Taiwan populations had $3 \mathrm{com}$ mon cohorts, with mean $\mathrm{R}-\mathrm{C}$ basal diameters of $4 \mathrm{~mm}$, $7.5 \mathrm{~mm}$ and $10 \mathrm{~mm}$.

\section{Sequence divergence and phylogenetic analysis}

The aligned COI fragments consisted of $624 \mathrm{bp}$, of which 124 of 195 polymorphic sites were parsimony informative. A total of 81 haplotypes was found among 108 sequences obtained from 12 populations of Chthamalus malayensis (Table 1). All representative haplotypes and sequences of the 2 outgroups C. moro and C. challengeri were deposited with GenBank (Accession nos. EU304363 - EU304448). 
Neighbor-joining (NJ) analysis of the 81 haplotypes revealed significant genetic structure within Chthamalus malayensis. Three clades were resolved with 100\% bootstrap support (Fig. 4). The first clade consisted mainly of samples from the South China Sea (hereafter, the South China Sea clade), including all individuals from the 3 sites in southern China, Thailand and some individuals from the NE coast of Taiwan. The second clade contained all samples from Singapore, Malaysia and the Indian Ocean (hereafter, the Indo-Malay clade); members of the third clade were found only in Taiwan (hereafter, the Taiwan clade). The 3 clades had an allopatric geographical distribution (Fig. 1), the NE coast of Taiwan being the only location where 2 clades (South China Sea and Taiwan clades) co-existed.

The sequence divergences among the 3 clades were high. The South China Sea clade was the most distantly related, differentiated by $\sim 12$ to $13 \%$ (range
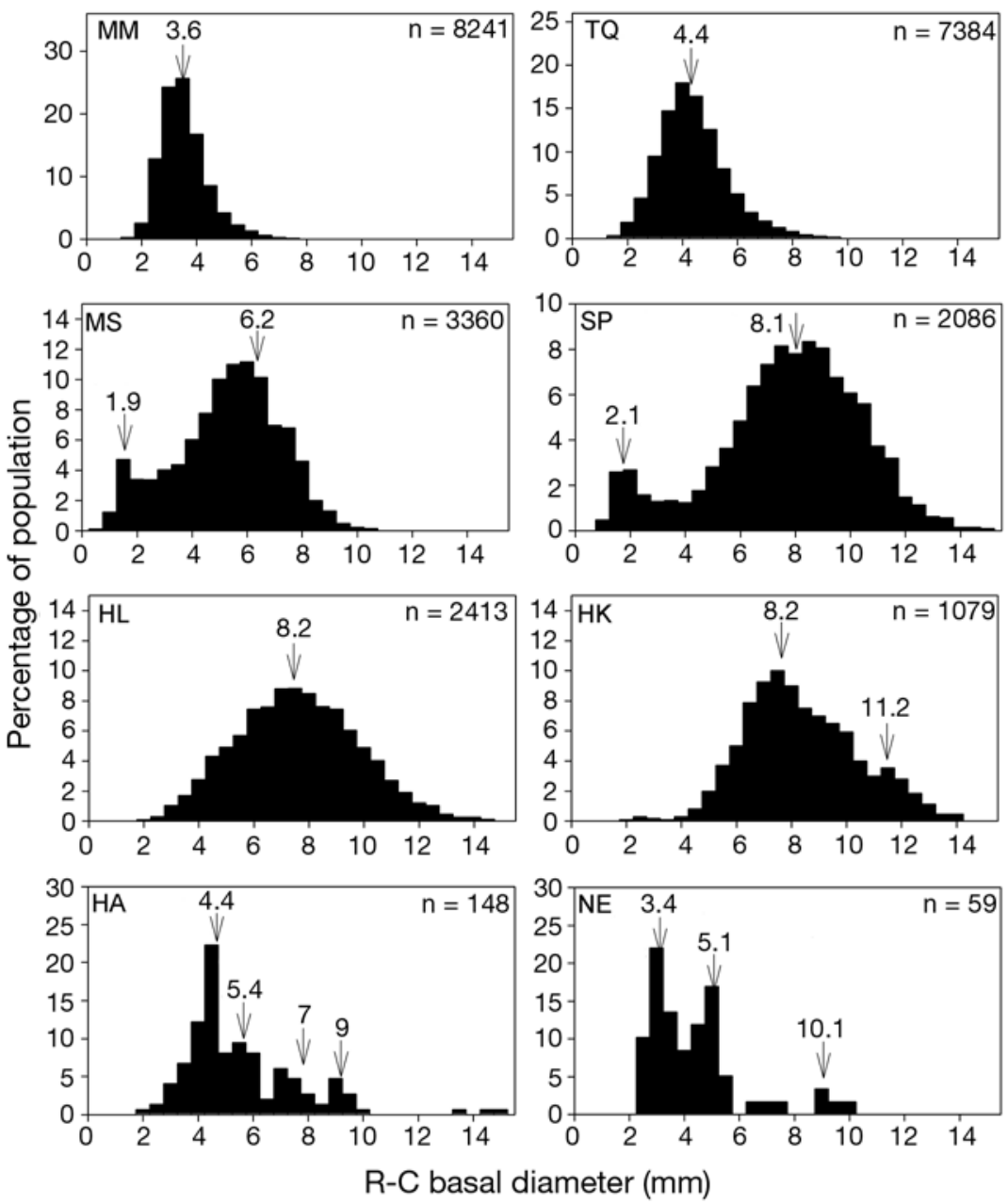

Fig. 3. Chthamalus malayensis. Variation in cohort structure. MM: Mahabalipuram; see Table 1 for abbreviations of other localities. Significant cohorts identified by ELEFAN (electronic length frequency analysis) are indicated by arrows and their mean $\mathrm{R}-\mathrm{C}$ (rostral-carinal) basal diameters (in $\mathrm{mm}$ ) are given. Note different scales on $y$-axis. $n$ : sample size
11 to $14.4 \%$ ) from the other 2 clades in the COI region. Conversely, the Indo-Malay and Taiwan clades differed by only $\sim 7.5 \%$ (range 7 to $8.5 \%$ ). These values were much greater than sequence divergences within each clade $(\leq 2.7 \%)$.

\section{Population genetic analysis and demographic history of the clades}

Since the divergence between clades was high, population genetic parameters were analyzed separately by clade. Haplotype and nucleotide diversity were highest for the South China Sea clade, whilst the Indo-Malay clade had the lowest genetic diversity (Tables 1 \& 2). The haplotype network for the South China Sea clade showed that individual haplotypes were randomly distributed within the network and were not clustered by location (Fig. 5a). Most haplotypes were sampled in only 1 individual. The Indo-Malay clade haplotype network was star-like, with 1 dominant haplotype ( $31 \%)$ shared by 4 of 5 populations in this clade (Fig. 5b). A majority of the other haplotypes differed from the dominant haplotype by only 1 to 3 mutations (Fig. 5b). No pattern could be observed in the Taiwan clade network due to the limited number of sequences (Fig. 5c).

Most pairwise $\Phi_{\mathrm{ST}}$ values between populations were small and non-significant within the 3 clades (Tables 3 \& 4), suggesting a lack of within-clade genetic structuring. For the Taiwan clade, the value between the 2 sites was -0.0195 , suggesting that the true value was near 0. For the Indo-Malay clade distributed across the Indian and Pacific Oceans, AMOVA revealed a lack of genetic differentiation between $\left(\Phi_{\mathrm{CT}}=-0.01, \mathrm{p}=0.49\right)$ and within oceans $\left(\Phi_{\mathrm{SC}}=0.01, \mathrm{p}=0.21\right)$. AMOVA was also performed by grouping Langkawi Island (Malaysia) in the Indian Ocean with the geographically more proximate Singapore and Mersing (Malaysia) populations instead of with Tranquebar and south Sri Lanka. This analysis also revealed little differentiation between the 2 groups $\left(\Phi_{\mathrm{CT}}=\right.$ $-0.04, \mathrm{p}=0.97$ ).

Mismatch distributions for all 3 clades were unimodal (Fig. 6), suggesting a rapid demographic expansion. This was 
Fig. 4. Chthamalus malayensis. Neighbour-joining (NJ) tree of COI (mitochondrial cytochrome $c$ oxidase subunit I) haplotypes. Percentages of bootstrap replicates are shown on the corresponding branches for all values $\geq 75$. Chthamalus challengeri and C. moro are used as outgroups. See Table 1 for abbreviations of localities

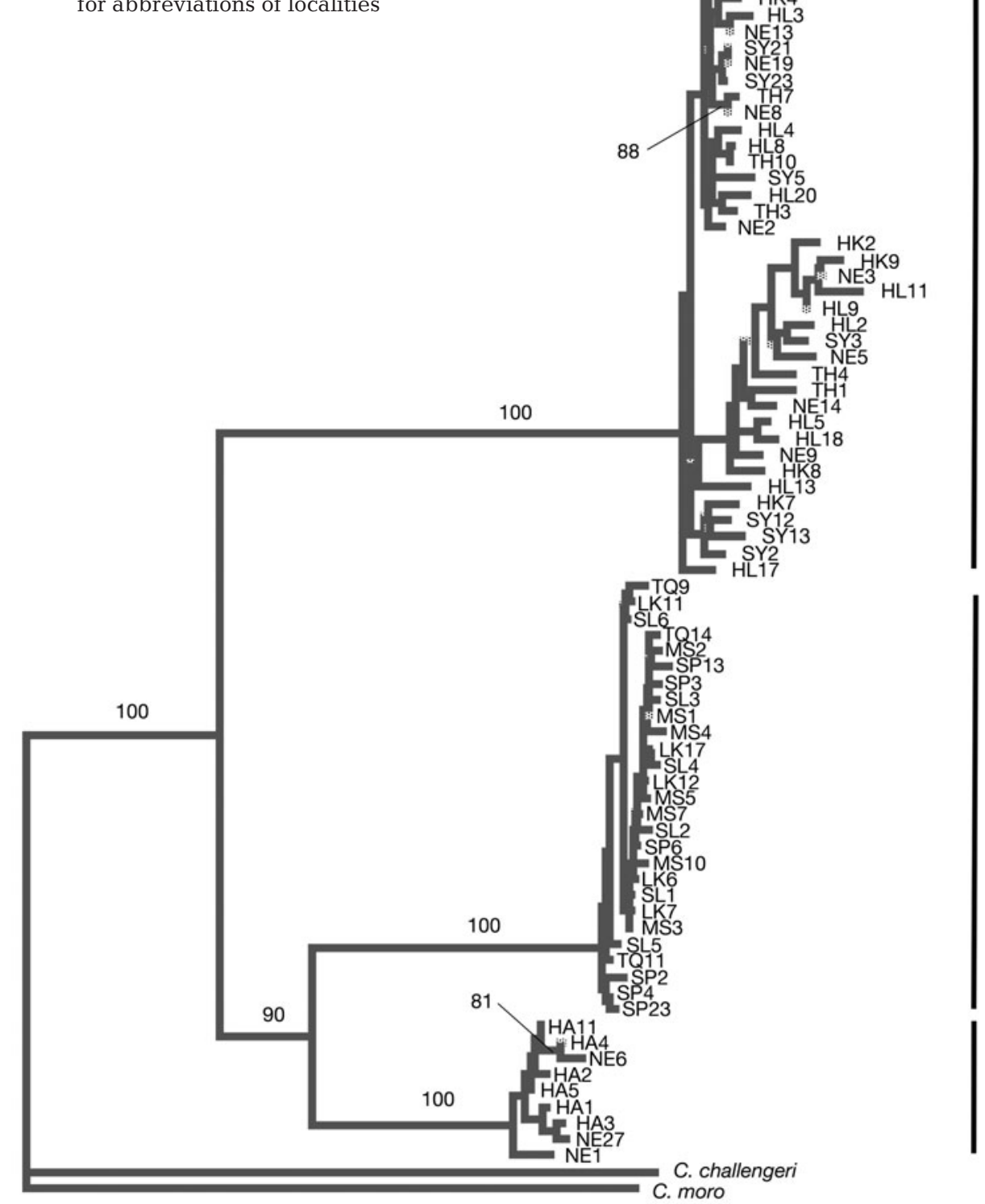

also supported by negative and significant Tajima's $D$ and Fu's $F_{\mathrm{S}}$ values for the South China Sea clade and the Indo-Malay clade (Table 2). The values of $D$ and $F_{\mathrm{S}}$ were smaller and less significant for the Taiwan clade, which might be due to the limited number of samples. We estimated $\tau$, which reflects the location of the crest of mismatch distribution, because we had observed a unimodal distribution for all 3 clades. $\tau$ was largest for the South China Sea clade, indicating earliest expansion in this clade (Table 2 ). $\tau$ values were comparable for the Taiwan and Indo-Malay clades. Using a one million year divergence rate of $3.1 \%$ between lineages (Wares 2001), the time of demographic expansion for the South China Sea, Taiwan and Indo-Malay clades were estimated as $450000 \mathrm{BP}, 126000 \mathrm{BP}$ and 88000 BP, respectively (Table 2).

\section{DISCUSSION}

\section{Cryptic diversity of Chthamalus malayensis}

Among the samples from Asia and the Indian Ocean, the common intertidal acorn barnacle Chthamalus malayensis consists of 3 distinct, highly diverged lineages. Mean COI sequence divergences among pairs 
Table 2. Chthamalus malayensis. Genetic diversity of the three clades. Sample size (n), number of haplotypes, haplotype diversity $(\mathrm{h} \pm \mathrm{SD})$, nucleotide diversity $(\pi \pm \mathrm{SD})$, Tajima's $D, F u$ 's $F_{\mathrm{S}}$, the mismatch parameter $\tau$ and the estimated time of expansion for each clade are shown. ${ }^{*} \mathrm{p}<0.05,{ }^{* *} \mathrm{p}<0.01,{ }^{* * *} \mathrm{p}<0.001$

\begin{tabular}{|lcccccrrr|}
\hline Clade & $\mathrm{n}$ & $\begin{array}{r}\text { Number of } \\
\text { haplotypes }\end{array}$ & $\mathrm{h} \pm \mathrm{SD}$ & $\pi \pm \mathrm{SD}$ & Tajima's $D$ & Fu's $F_{\mathrm{s}}$ & $\begin{array}{r}\tau \\
\text { Estimated time } \\
\text { of expansion }\end{array}$ \\
\hline South China Sea clade & 48 & 45 & $0.997 \pm 0.005$ & $0.013 \pm 0.007$ & $-1.78^{*}$ & $-24.88^{* * *}$ & 8.711 & $450000 \mathrm{BP}$ \\
Indo-Malay clade & 48 & 27 & $0.900 \pm 0.039$ & $0.004 \pm 0.002$ & $-2.15^{* * *}$ & $-26.46^{* * *}$ & 1.711 & $88000 \mathrm{BP}$ \\
Taiwan clade & 12 & 9 & $0.909 \pm 0.080$ & $0.007 \pm 0.004$ & -1.19 & $-2.87^{*}$ & 2.434 & $126000 \mathrm{BP}$ \\
\hline
\end{tabular}

of the 3 clades ( 7.5 to $13 \%)$ approach the magnitude of interspecific values for other Chthamalus ( 15\%) species and another acorn barnacle genus Euraphia ( 9\%) (Wares 2001). The sequence divergence between the Taiwan and Indo-Malay clades was the lowest, $(\sim 7.5 \%)$, indicating that the 2 diverged relatively recently. This close association was unexpected, as the geographical ranges of the 2 do not overlap (based on our sampling). The degree of genetic divergence between the Taiwan and Indo-Malay clades was smaller than that between recognized species of other acorn barnacles (loc. cit.), and it remains to be seen whether these 2 clades of $C$. malayensis are reproductively isolated.

The 3 clades we identified also differed ecologically. The South China Sea clade was restricted to the high shore, whilst the Indo-Malay clade inhabited the mid to low shore. Moreover, the Indo-Malay clade was the dominant space occupant with a cover of $>50 \%$ (cf. $\sim 50 \%$ cover measured for the South China Sea clade). The Taiwan clade was very sparsely distributed on the shore. There are differences in reproductive seasonality between Hong Kong and Singapore Chthamalus malayensis populations (Koh et al. 2005, Yan et al. 2006). These 2 populations correspond to the South China Sea and Indo-Malay clades in our present study, suggesting that there are physiological differences between the clades as well as genetic and ecological differences. Integrating all of these observations, it is apparent that there are at least 2 species present in the currently recognized C. malayensis. The South China Sea clade has an independent gene pool and, therefore, should be considered as a distinct species, while the species status of the genetically less differentiated Taiwan and IndoMalay clades requires further analyses using nuclear DNA markers and morphological features.

\section{Postglacial expansion, colonization and recent connectivity across oceans}

Both mismatch distribution analysis and neutrality tests indicated population expansion in the 3 clades. This may be attributed to range expansion following the Pleistocene glaciation. During the Pleistocene, lowering sea levels led to changes in temperature, habitat availability and ocean current patterns that would have dramatically affected the distribution and abundance of marine organisms (Hewitt 2000). Species went extinct over large parts of their range during the glacial maxima, with only a small number of individuals surviving in refugia. Species ranges expanded again from their refugia following retreat of the glaciers (Hewitt 2000). This likely resulted in the high haplotype diversity but relatively low nucleotide diversity we observed in the 3 clades of barnacles.

However, the timing of range expansion differed among the 3 clades. The South China Sea clade was the earliest to expand, whilst the Indo-Malay clade showed the most recent expansion. These differences may be the result of differences in geographic ranges. Large areas of land were exposed in the Sunda Shelf during the Pleistocene (Voris 2000), leading to isolation and large-scale range contraction in marine organism distributions. Thus, the Indo-Malay clade in this region might have experienced a greater contraction in population size and distribution range and was only able to attain its present range after the sea level approached its present-day level. In contrast, the distribution ranges of the other 2 clades are likely to have fluctuated less (Voris 2000). Although there were also range shifts during glaciation, considerable areas of coastal habitat in the South China Sea and western Pacific regions remained in which intertidal species were able to survive. Thus, the differences in geographic range among the 3 clades seem to have resulted in different demographic histories.

Phylogeographic subdivision is lacking between Pacific and Indian Ocean populations in the IndoMalay clade of Chthamalus malayensis. There are 2 possible explanations for this observation. Firstly, the high level of present-day gene flow may have eroded any signature of historical isolation. However, this factor alone does not seem to be a satisfactory explanation for the pattern. If the Pacific and Indian Ocean populations were separated during the Pleistocene, and then came into secondary contact through recent gene flow, divergent haplotypes should be observed even though 
hybridization occurred (Hewitt 2000). However, the genetic diversity of both the Pacific and Indian populations is low, and all haplotypes differ by only a few mutational steps, so that this hypothesis is not supported. On the other hand, the low genetic diversity suggests an alternative explanation of recent postglacial colonization from the Pacific to the Indian Ocean. This might have been achieved by transport of a few planktonic larvae westward from the Pacific through the Indonesian seas, with final settlement in the Indian Ocean (Gordon \& Fine 1996). The unimodal mismatch distribution supports this hypothesis. Similar scenarios have also been observed in other IWP taxa (e.g. Lessios et al. 2003) and in the Atlantic-Mediterranean region, where species without population structure have undergone demographic expansion following Pleistocene glaciations (Patarnello et al. 2007).

The founder effect during re-colonization may have also led to a reduction in genetic diversity and shift in haplotype frequency in the Indian Ocean populations, resulting in genetic differentiation between the Pacific and Indian Ocean populations. Moreover, the island chain of the Indo-Malaysian archipelago and Australia limits the current flow between the 2 oceans and would thus restrict larval dispersal. Yet there is clear genetic homogeneity between the 2 oceans and their populations share common haplotypes, indicating considerable contemporary gene flow. However, the populations in India have a different cohort structure from those in Singapore and Malaysia, which are similar in this respect, suggesting that the larval supply sources differ between India and the east coast of the Malay Peninsula. Hence, the connectivity of $C$. malayensis populations between the 2 oceans may be restricted on an ecological time scale, but not on an evolutionary time scale. Dispersal on an ecological time scale would not be detected by mtDNA, which is less sensitive to genetic drift, compared to more variable markers such as microsatellites (Avise 2000).

\section{Biogeography of the western Pacific intertidal}

It appears paradoxical that the Indo-Malay clade of Chthamalus malayensis has a relatively restricted distribution only in the western Pacific, despite its ability to disperse across the 2 oceans. Factors other than dispersal capacity seem to play a role in determining the biogeographic structure of the 3 clades. The South China Sea and the neighboring areas have a dynamic hydrology that greatly affects the dispersal and distribution of marine taxa (Gordon \& Fine 1996, Guan \& Fang 2006). Comparison of the distributions of the 3 clades of $C$. malayensis with those of the sympatric Tetraclita squamosa species complex (which

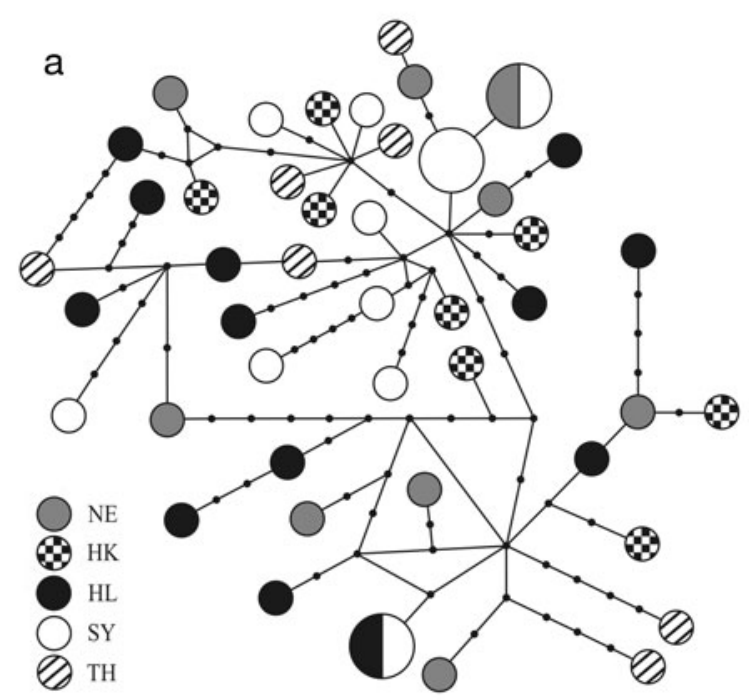

b

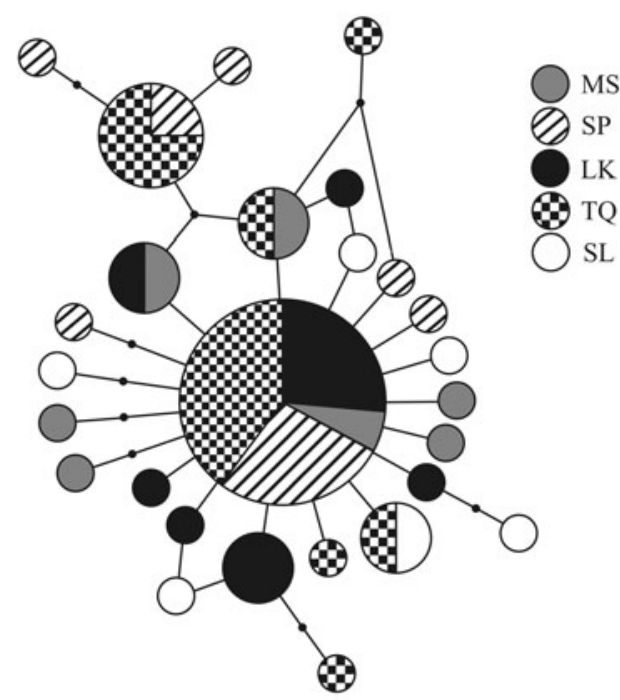

C

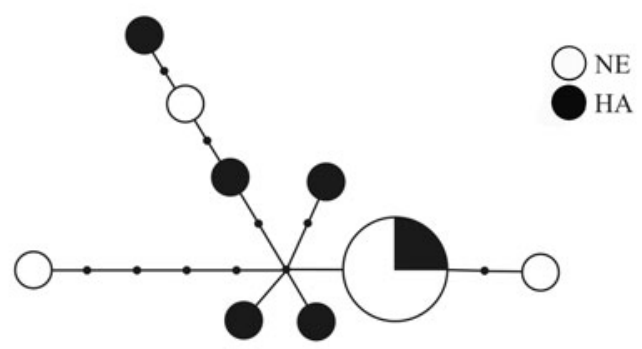

Fig. 5. Chthamalus malayensis. COI (mitochondrial cytochrome $c$ oxidase subunit I) haplotype network of (a) South China Sea clade, (b) Indo-Malay clade, and (c) Taiwan clade. Nodes along each branch designate the number of base differences among haplotypes. Patterns within the circles denote localities (see Table 1 for abbreviations), circle areas are proportional to the number of individuals within the particular haplotype 
Table 3. Chthamalus malayensis. Pairwise $\Phi_{\mathrm{ST}}$ values for populations of the South China Sea clade based on COI (mitochondrial cytochrome $c$ oxidase subunit I). ${ }^{*} \mathrm{p}<0.05$. See Table 1 for abbreviations of localities

\begin{tabular}{lrrrr|}
\hline Population & NE & HK & HL & SY \\
\hline HK & -0.0447 & & & \\
HL & -0.0194 & 0.0004 & & \\
SY & 0.0363 & 0.0241 & $0.0897^{*}$ & \\
TH & -0.0322 & -0.0255 & 0.0064 & -0.0105 \\
\hline
\end{tabular}

Table 4. Chthamalus malayensis. Pairwise $\Phi_{\mathrm{ST}}$ values for populations of Indo-Malay clade based on COI (mitochondrial cytochrome $c$ oxidase subunit I). ${ }^{*} p<0.05$. See Table 1 for abbreviations of localities

\begin{tabular}{|lcccc|}
\hline Population & MS & SP & LK & TQ \\
\hline SP & -0.0043 & & & \\
LK & -0.0057 & 0.0531 & & \\
TQ & -0.0022 & -0.0430 & 0.0291 & \\
SL & 0.0049 & $0.0688^{*}$ & -0.0286 & 0.0681 \\
\hline
\end{tabular}

also consists of 3 species with overlapping ranges, Chan et al. 2007a,b), reveals a certain degree of concordance between the 2 groups. The coast of southern China is dominated by $T$. squamosa and the South China Sea clade of C. malayensis, while T. kuroshioensis and the Taiwan clade of C. malayensis are the major inhabitants in eastern Taiwan (Chan et al. 2007a). The southern China coast is under the influence of the South China Sea Current, while the Kuroshio Current is prevalent in east Taiwan (Guan \& Fang 2006). Variation in larval supply, driven by the distinct ocean current systems, may contribute to the observed distributions. Further south, towards tropical SE Asia, these species are replaced by $T$. singaporensis and the Indo-Malay clade of C. malayensis in Singapore (Chan et al. 2007b). This genetic transition also occurs in the wrasse Thallasoma hardwicki and is attributable to complex local circulation patterns that block gene flow between the northern and southern parts of the South China Sea (Chen et al. 2004). Thus, the ocean current configuration may play an important role in determining the genetic structures and species ranges in the western Pacific intertidal. Restrictions in water currents and gene flows between the ocean systems may result in the variation in barnacle cohort structure (see Jenkins et al. 2001). Cohort structure of C. malayensis differs among (1) Malaysia and Singapore, (2) southern China and (3) Taiwan waters, but within each of these regions there is similarity in cohort structure, suggesting that the patterns of larval supply and gene flow (which are related to ocean currents) differ among regions.
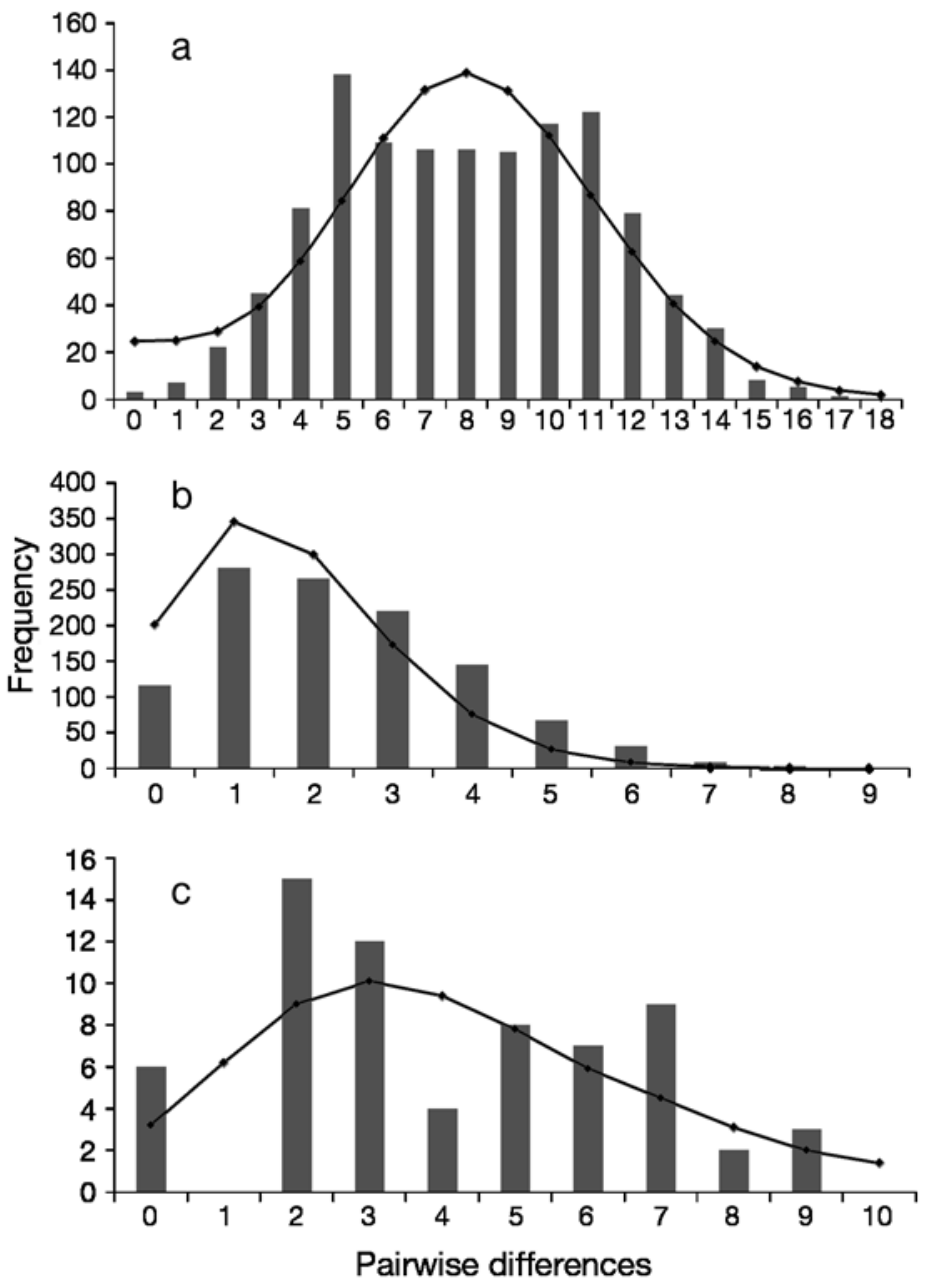

Fig. 6. Chthamalus malayensis. Observed (bars) and expected (line) mismatch distributions under a model of sudden demographic expansion for COI (mitochondrial cytochrome $c$ oxidase subunit I) haplotypes: (a) South China Sea clade, (b) Indo-Malay clade, and (c) Taiwan clade. Harpending's raggedness indices: $r=0.008(\mathrm{p}=0.70)$ for the South China Sea clade, $r=0.034(\mathrm{p}=0.76)$ for the Indo-Malay clade, and $r=0.095(\mathrm{p}=0.15)$ for the Taiwan clade

In addition to the physical dispersal pattern, the interactions of local physical and biological factors will contribute to maintaining allopatric distribution of the species. The 3 clades of Chthamalus malayensis have different vertical zonations and abundances in the intertidal zone, suggesting that they may respond differently to environmental factors. The major factors known to determine the upper shore limit of barnacles are post-settlement mortality, induced by heat stress (Southward 1962, Chan et al. 2006), and competition with other species (Connell 1961). In Indo-Malay waters, the Indo-Malay clade of C. malayensis is the most common barnacle and the major space occupant on the mid shore; Tetraclita is much less abundant. 
Along the coast of southern China, the mid shore is dominated by T. squamosa and T. japonica japonica, while the South China Sea clade of C. malayensis is restricted to the high shore. This distribution pattern may be related to the higher tolerance of this clade to heat stress, or avoidance of competition with Tetraclita species. In Taiwan, the abundance of C. malayensis (the Taiwan clade) was the lowest among the areas studied, and individuals were sparsely distributed within the Tetraclita zone in the mid and high shore. Such variations in zonation pattern among the 3 clades of C. malayensis also occur in Tetraclita (Chan et al. 2008). In Singapore, only $T$. singaporensis has been recorded and it occurs in the mid shore (B. Chan pers. obs.). In Hong Kong, 2 Tetraclita species have a distinct vertical separation, with T. squamosa on the low shore and T. japonica on the mid shore. In Taiwan, T. kuroshioensis and T. japonica formosana occur together on the mid shore (Chan et al. 2008). Thus, biological interaction appears to be a factor affecting the geographical ranges of barnacles, and probably the ranges of other fauna.

Our study indicates that there is likely a high level of hidden biodiversity within the IWP intertidal biota awaiting discovery and investigation. The interactions between biological attributes among lineages and environmental factors shape genetic structure and distribution across the range of the barnacle species complex. Thus, studies which focus solely on genetic differentiation among populations in relation to physical factors such as ocean current pattern will not fully elucidate the origin of high levels of biodiversity in the IWP. Information on the ecology of individual taxa should also be considered in order to interpret and understand the biogeographic patterns observed.

Acknowledgements. We thank C. H. Hsu and P. C. Tsai (Academia Sinica, Taiwan) for assisting with the field work in India, Malaysia and Singapore. J. True (The University of Hong Kong) and M. Ganmanee (King Mongkut's Institute of Technology Ladkrabang, Thailand) assisted with collections in Sri Chang Island, Thailand. J. Leung (The University of Hong Kong) collected specimens from Sri Lanka. The authors thank the late Prof. Alan Southward for his advice during the study. The work was partially supported by a grant from the Research Grants Council, Hong Kong SAR (HKU7597/05M), a research grant from the National Science Council, Taiwan (NSC 96-2621-B-001-007-MY3) and an internal research grant from Academia Sinica, Taiwan.

\section{LITERATURE CITED}

Avise JC (2000) Phylogeography: the history and formation of species. Harvard University Press, Cambridge, MA

Benzie JAH (1999) Genetic structure of coral reef organisms: ghosts of dispersal past. Am Zool 39:131-145

Bertness MD, Gaines SD, Yeh SM (1998) Making mountains out of barnacles: the dynamics of acorn barnacle hummocking. Ecology 79:1382-1394

Bickford D, Lohman DJ, Sodhi NS, Ng PKL and others (2007) Cryptic species as a window on diversity and conservation. Trends Ecol Evol 22:148-155

Briggs JC (1999) Coincident biogeographic patterns: IndoWest Pacific Ocean. Evolution 53:326-335

Chan BKK, Williams GA (2004) Population dynamics of the acorn barnacles, Tetraclita squamosa and Tetraclita japonica (Cirripedia: Balanomorpha) in Hong Kong. Mar Biol 146:149-160

Chan BKK, Morritt DM, Pirro MD, Leung KMY, Williams GA (2006) Summer mortality: effects on the distribution and abundance of the acorn barnacle Tetraclita japonica on tropical shores. Mar Ecol Prog Ser 328:195-204

Chan BKK, Tsang LM, Chu KH (2007a) Morphological and genetic differentiation of Tetraclita squamosa (Crustacea, Cirripedia) in East Asia and description of a new species of Tetraclita. Zool Scr 36:79-91

Chan BKK, Tsang LM, Chu KH (2007b) Cryptic diversity of Tetraclita squamosa complex (Crustacea, Cirripedia) in Asia: description of a new species from Singapore. Zool Stud 46:46-56

Chan BKK, Murata A, Lee PF (2008) Latitudinal gradient in the distribution of intertidal barnacles of the Tetraclita species complex in Asian waters. Mar Ecol Prog Ser 362: 201-210

Chen CA, Ablan MCA, McManus JW, Bell JD, Tuan VS, Cabanban AS, Shao KT (2004) Population structure and genetic variability of six bar wrasse (Thallasoma hardwicki) in northern South China Sea revealed by mitochondrial control region sequences. Mar Biotechnol 6:312-326

Clement M, Posada D, Crandall KA (2000) TCS: a computer program to estimate gene genealogies. Mol Ecol 9: $1657-1660$

Connell JH (1961) The influence of interspecific competition and other factors on the distribution of the barnacle Chthamalus stellatus. Ecology 42:710-723

> Craig MT, Eble JA, Bowen BW, Robertson DR (2007) High genetic connectivity across the Indian and Pacific Oceans in the reef fish Myripristis berndti (Holocentridae). Mar Ecol Prog Ser 334:245-254

Excoffier L, Smouse PE, Quattro JM (1992) Analysis of molecular variance inferred from metric distances among DNA haplotypes: application to human mitochondrial DNA restriction data. Genetics 86:991-1000

Excoffier L, Laval LG, Schneider S (2005) Arlequin ver. 3.0: An integrated software package for population genetics data analysis. Evol Bioinform Online 1:47-50

Folmer O, Black M, Hoeh W, Lutz RA, Vrijenhoek RC (1994) DNA primers for amplification of mitochondrial cytochrome $c$ oxidase subunit I from diverse metazoan invertebrates. Mol Mar Biol Biotechnol 3:294-299

> Fu YX (1997) Statistical tests of neutrality of mutations against population growth, hitchhiking and background selection. Genetics 147:915-925

> Gordon AL, Fine RA (1996) Pathways of water between the Pacific and Indian oceans in the Indonesian seas. Nature 379:146-149

Guan B, Fang G (2006) Winter counter-wind currents off the southeastern China coast: a review. J Oceanogr 62:1-24

Hewitt GM (2000) The genetic legacy of the Quaternary ice ages. Nature 405:907-913

> Hughes TP, Bellwood DR, Connolly SR (2002) Biodiversity hotspots, centres of endemicity, and the conservation of coral reefs. Ecol Lett 5:775-784

Jenkins SR, Åberg P, Cervin G, Coleman RA and others 
(2001) Population dynamics of the intertidal barnacle Semibalanus balanoides at three European locations: spatial scales of variability. Mar Ecol Prog Ser 217:207-217

Koh LL, O'Riordan RM, Lee WJ (2005) Sex in the tropics: reproduction of Chthamalus malayensis Pilsbry (Class Cirripedia) at the equator. Mar Biol 147:121-133

Lessios HA, Kane J, Robertson DR (2003) Phylogeography of the pantropical sea urchin Tripneustes: contrasting patterns of population structure between oceans. Evolution 57:2026-2036

Meyer CP, Geller JB, Paulay G (2005) Fine scale endemism on coral reefs: archipelagic differentiation in turbinid gastropods. Evolution 59:113-125

Mora C, Sale PF (2002) Are populations of coral reef fish open or closed? Trends Ecol Evol 17:422-428

Pannacciulli FG, Bishop JDD, Hawkins SJ (1997) Genetic structure of populations of two species of Chthamalus (Crustacea: Cirripedia) in the north-east Atlantic and Mediterranean. Mar Biol 128:73-82

Patarnello T, Volckaert FAMJ, Castilho R (2007) Pillars of Hercules: is the Atlantic-Mediterranean transition a phylogeographical break? Mol Ecol 16:4426-4444

Reimer AA (1976) Description of a Tetraclita stalactifera panamensis community on a rocky intertidal Pacific shore of Panama. Mar Biol 35:239-251

Rogers AR, Harpending H (1992) Population growth makes waves in the distribution of pairwise genetic differences. Mol Biol Evol 9:552-569

Schneider S, Excoffier L (1999) Estimation of past demographic parameters from the distribution of pairwise differences when the mutation rates vary among sites: application to human mitochondrial DNA. Genetics 152: 1079-1089

Southward AJ (1962) On the behavior of barnacles. IV: The influences of temperature on cirral activity and survival

Editorial responsibility: Inna Sokolova,

Charlotte, North Carolina, USA of some warm-water species. J Mar Biol Assoc UK 42: 163-177

Southward AJ, Newman WA (2003) A review of some common Indo-Malayan and western Pacific species of Chthamalus barnacles (Crustacea: Cirripedia). J Mar Biol Assoc UK 83:797-812

Swofford DL (2000) PAUP*: phylogenetic analysis using parsimony ( ${ }^{*}$ and other methods), ver 4 . Sinauer, Sunderland, MA

Tajima F (1989) Statistical method for testing the neutral mutation hypothesis by DNA polymorphism. Genetics 123:585-596

Taylor MS, Hellberg ME (2003) Genetic evidence for local retention of pelagic larvae in a Caribbean reef fish. Science 299:107-109

Thompson JD, Higgins DG, Gibson TJ (1994) Clustal W: improving the sensitivity of progressive multiple sequence alignment through sequence weighting, position-specific gap penalties and weight matrix choice. Proc Natl Acad Sci USA 22:4673-4680

> Tsang LM, Chan BKK, Ma KY, Hsu CH, Chu KH (2007) Lack of mtDNA and morphological differentiation between two acorn barnacles Tetraclita japonica and T. formosana differing in parietes colours and geographical distribution. Mar Biol 151:147-155

> Voris HK (2000) Maps of Pleistocene sea levels in Southeast Asia: shorelines, river systems and time durations. J Biogeogr 27:1153-1167

Wares JP (2001) Patterns of speciation inferred from mitochondrial DNA in North American Chthamalus (Cirripedia: Balanomorpha: Chthamaloidea). Mol Phylogenet Evol 18:104-116

> Yan Y, Chan BKK, Williams GA (2006) Reproductive development of the barnacle Chthamalus malayensis in Hong Kong: implications for the life-history patterns of barnacles on seasonal, tropical shores. Mar Biol 148:875-887

Submitted: December 3, 2007; Accepted: March 13, 2008 Proofs received from author(s): July 12, 2008 